\title{
Online Drilling Fluid Flowmetering in Open Channels with Ultrasonic Level Sensors using Critical Depths
}

\author{
Khim Chhantyal Håkon Viumdal Saba Mylvaganam \\ Faculty of Technology, Natural Sciences, and Maritime Sciences, University College of Southeast Norway, \\ $\{$ khim. chhantyal, hakon.viumdal, saba.mylvaganam $\}$ @usn. no
}

\begin{abstract}
In drilling operations, non-Newtonian drilling fluid is continuously circulated in a closed loop. One of the ways to monitor and regulate drilling operations is by accurately measuring the flow rate of circulating drilling fluid before entering and after returning from the wellbore. The circulating fluid flows in an open channel on the return path from the wellbore. This work investigates the use of Venturi constriction to estimate the non-Newtonian fluid flow in an open channel. Based on the specific energy principle, a relation between volumetric flow rate and critical depth is developed, which is used to estimate the flow rate based on the measured critical depth. To measure a critical depth for a given flow rate, it is necessary to locate a critical depth position in the Venturi flume. In this study, the critical depth position is located using specific energy diagram (at a minimum specific energy within the Venturi constriction) and Froude Number approach (at a Froude Number equals to 1). Based on the identified critical depth, the flow conditions (subcritical, critical or supercritical) along the Venturi flume are observed. The location of the critical depth in the Venturi section is found by performing experiments at $350[\mathrm{~kg} / \mathrm{min}]$ flow rate of the fluid. Further, the developed critical depth flow model is tested for randomly varying flow rates (250-500 $[\mathrm{kg} / \mathrm{min}])$ with the identified critical depth location. The flow estimations of the model were within the acceptable limit. However, it is found that the estimates for 350 $[\mathrm{kg} / \mathrm{min}]$ are comparatively more accurate, which proves that the critical depth and critical depth position depends on the flow rate and rheological properties.
\end{abstract}

Keywords: open channel Venturi flume, non-Newtonian flow, critical depth, ultrasonic scanning of open channel flow

\section{Introduction}

Open channel flow is a flow of fluid in conduct with a free surface. Examples of open channel flow are rivers, irrigation ditches, canals, storm and sanitary sewer systems, industrial waste applications, sewage treatment plants, transportation of non-Newtonian slurries, etc. In this work, a non-Newtonian drilling fluid flow in the open channel is studied.

The drilling fluids used in the oil \& gas industries are
non-Newtonian, which helps:

- to keep the bottom-hole pressure within a pressure window of acceptable margins to prevent kicks and their losses into down-hole environment,

- to lubricate the drill bit, and

- to remove swiftly the cuttings and debris from down-hole due to their high viscous nature.

In drilling operations, the drilling fluid is continuously pumped down to wellbore through the drill pipe and is circulated through the annulus back to the surface where the flow is conducted in an open channel.(Caenn et al., 2011)

One way of maintaining the stability of bottom-hole pressure is by monitoring and regulating the drilling fluid flow rate. An early indication of wellbore instability can be detected using delta flow method, which is based on the difference between inflow and outflow measurements of drilling fluid while circulating the fluid, (Maus et al., 1979; Speers and Gehrig, 1987; Orban et al., 1987; Orban and Zanker, 1988; Schafer et al., 1992; Lloyd et al., 1990). Therefore, it is important to measure inflow and outflow of drilling fluid accurately. It is convenient to measure inflow accurately, as drilling fluids flowing in have known rheological properties with negligible impurities. In literature (Orban et al., 1987; Orban and Zanker, 1988; Schafer et al., 1992), flow meters like conventional pump stroke counter, rotatory pump speed counter, magnetic flow meter, ultrasonic Doppler flow meter, and Coriolis mass flow meter can be used to measure the inflow. However, it is difficult to accurately measure the outflow as the returning fluid contains rock cuttings, formation gases, and formation liquids. In literature (Orban et al., 1987; Orban and Zanker, 1988; Schafer et al., 1992), flow meters like standard paddle meter, ultrasonic level meter, a prototype rolling float meter, magnetic flow meter, and Venturi flow meter can be used to measure the outflow. In recent years, Rainer Haldenwang and his research group has performed several open channel flow studies in different cross-sectional shapes, (Burger et al., 2010, 2014; Kabwe et al., 2017). Our study focuses on the use of Venturi flow meter in an open channel for drilling fluid flow measurement. 


\section{System Description}

A flow loop is available at University College of Southeast Norway (USN), Porsgrunn Campus for the study of drilling fluid flow through an open channel Venturi flume. The flow loop consist of a trapezoidal cross-sectional open channel with Venturi constriction as shown in Figure 1 and Figure 2. The flume can be inclined upto 2 degrees angle to the horizontal. There are three adjustable ultrasonic level sensors above the flume for flow depth measurements at different section of the flume. Different model-drilling fluids are available for testing purposes. For this study, a water-based non-Newtonian shear thinning fluid with a density of $1153 \mathrm{~kg} / \mathrm{m}^{3}$ and viscosity of approximately $23-100 c P$ for corresponding shear rates of $500-1$ $s^{-1}$ is used. A centrifugal pump is used to circulate model-drilling fluids in the flow loop through the open channel.

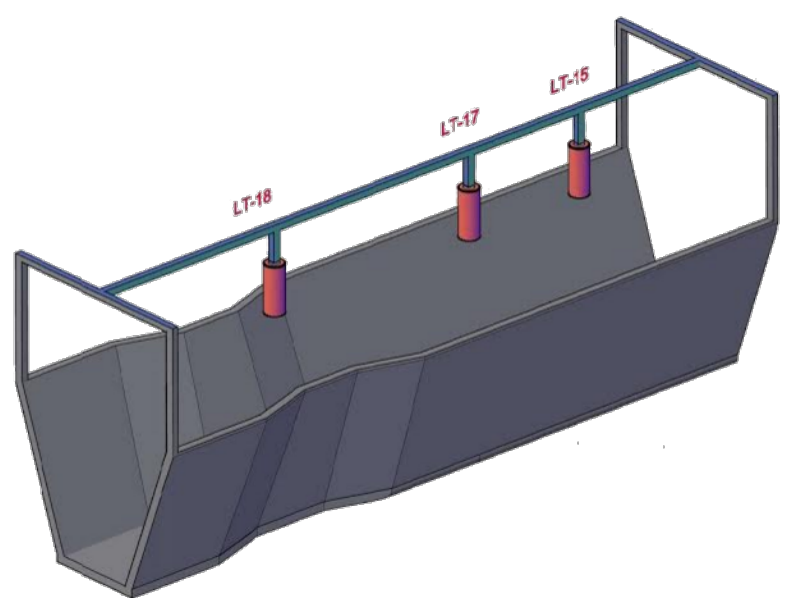

Figure 1. An open channel with Venturi constriction and three ultrasonic level sensors (LT-15, LT-17, and LT-18). (Chhantyal et al., 2016)

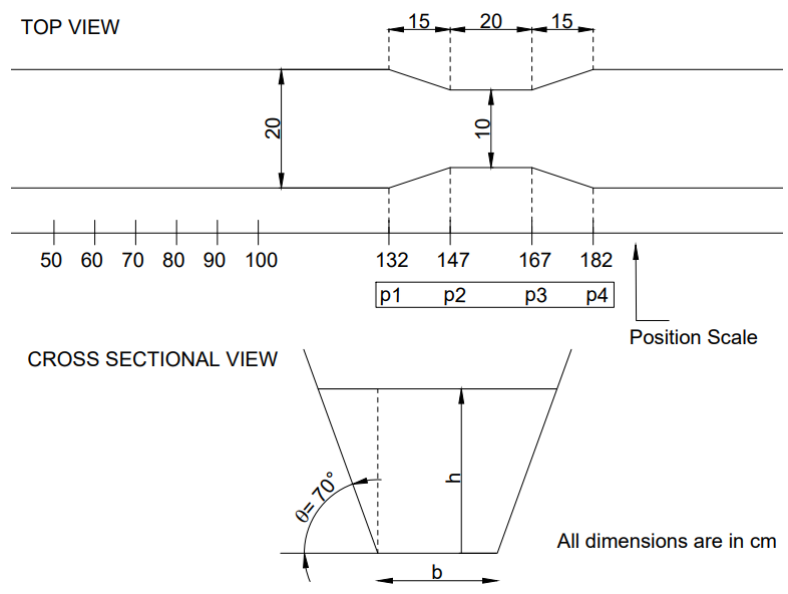

Figure 2. Top and cross sectional view of open channel Venturi flume with the position scale in centimetres. The Venturi constriction is shown in three sections with positions $\mathrm{p} 1-\mathrm{p} 2$ as converging section, positions $\mathrm{p} 2-\mathrm{p} 3$ as throat section, and $\mathrm{p} 3-\mathrm{p} 4$ as diverging section.

\section{Methods}

For a steady and incompressible fluid flow, the total energy remains constant along the horizontal flow conduct. The Bernoulli flow principle gives the energy equation of the flow as,

$$
P+\rho g z+\frac{\rho v^{2}}{2}=\text { constant }
$$

where $P$ is applied pressure, $\rho$ is fluid density, $g$ is acceleration due to gravity, $z$ is elevation, and $v$ is average fluid velocity.

Dividing Equation 1 by specific weight $(\gamma=\rho g)$ gives specific energy equation as in Equation 2.

$$
E_{s}=h+z+\frac{v^{2}}{2 g}
$$

where $h$ is fluid depth.

If the bottom surface of the conduct is considered as the datum, we can use $z=0$ and Equation 2 becomes,

$$
E_{s}=h+\frac{v^{2}}{2 g}
$$

where $E_{s}$ is the specific energy of fluid and is dependent on fluid depth and velocity of the fluid.

In open channel flow, the surface or profile of fluid flow is studied using Hydraulic Grade Line (HGL) and Energy Grade Line (EGL), which are defined by Equation 4 and Equation 5 respectively.

$$
\begin{gathered}
H G L=h \\
E G L=h+\frac{v^{2}}{2 g}
\end{gathered}
$$

Further using $Q=v \cdot A$, Equation 3 can be rewritten as,

$$
E_{s}=h+\frac{(Q / A)^{2}}{2 g}
$$

where $Q$ is volumetric flow rate, and $A$ is the cross-sectional area. For a trapezoidal channel, the cross-sectional area is $A=h(b+h \cot \theta)$ where $b$ is the bottom width of the channel and $\theta$ is the slope angle of the channel walls shown in Figure 2. Hence, the Equation 6 becomes,

$$
E_{s}=h+\frac{Q^{2}}{2 g h^{2}(b+h \cot \theta)^{2}}
$$

Using Equation 7, a specific energy diagram showing the relation between specific energy $\left(E_{s}\right)$ vs. flow depth (h) can be developed for a given flow rate. From the specific energy diagram, different flow conditions (subcritical, critical, or supercritical) can be identified. For every value of given flow rate, there is a corresponding associated critical depth, $h_{c}$. Flow with a depth greater than the critical depth is a subcritical flow and flow with a 
depth less than the critical depth is a supercritical flow. In subcritical flow, the potential energy component is large and in supercritical flow, the kinetic energy component is large. Whereas, the critical depth is a position having the minimum specific energy for the given flow rate in the specific energy diagram. Hence, the critical depth can be identified by equating the first derivative of Equation 7 to zero.

$$
\frac{d E_{s}}{d h}=0, \text { for } h=h_{c}
$$

Using Equation 7 and Equation 8 with several mathematical simplifications, the flow rate and the critical depth relation can be obtained as in Equation 9,

$$
Q=\left[\frac{g h_{c}^{3}\left(b+h_{c} \cot \theta\right)^{3}}{b+2 h_{c} \cot \theta}\right]^{1 / 2}
$$

In addition, Froude Number can be used to identify the critical depth. The dimensionless Froude Number for shallow fluid flow is given as the ratio of flow inertia to the wave velocity as in Equation 10,

$$
F r=\frac{v}{\sqrt{g(A / B)}}
$$

where $F r$ is Froude Number and $B$ is the free surface width. For $F r<1$ flow is subcritical flow, $F r>1$ flow is supercritical flow, and for $F r \approx 1$ flow is critical flow.

For detail study on open channel flow energy principles, refer to (Featherstone and Nalluri, 1982; Chaudhry, 2007).

\section{Results}

To study the flow profile and identify the critical depth, the model-drilling fluid is circulated at five different flow rates $(Q=275,300,350,400,450[\mathrm{~kg} / \mathrm{min}])$ in 12 different experimental set-ups. In each experimental set-up, the three ultrasonic level measurements are uniquely positioned along the Venturi-flume. As a result, 36 different flow depths are logged for each flow rate. These flow depths are used to locate critical depth along the Venturi constriction. Finally, the randomly varying flow rates are estimated using the critical depth.

\subsection{Flow Profile Study}

To study the flow profile, 36 different flow depths at the flow rate of $350[\mathrm{~kg} / \mathrm{min}]$ are fitted using an Artificial Neural Network (ANN) based polynomial. Thus obtained ANN based polynomial model for flow depth along the Venturi flume is further used to plot Hydraulic Grade Line (HGL) and Energy Grade Line (EGL) as shown in Figure 3. The HGL shows the steady upstream depth and is gradually reducing as the fluid flows through the constriction. EGL represents the total energy head available for the fluid at given flow rate. Within the constriction, EGL has a convex shape with a minimum specific energy, which represents the critical depth.

\subsection{Specific Energy Diagram}

Figure 4 a shows a specific energy diagram within the Venturi constriction for the flow rate of $350[\mathrm{~kg} / \mathrm{min}]$. Locating the minimum specific energy in the specific energy diagram, critical fluid depth is identified for the given flow rate. Any flow with flow depth greater than identified critical depth is subcritical flow and flow with a depth less than the critical depth is supercritical flow as shown in Figure 4a.

To identify the position of critical depth along the Venturi throat section, specific energy vs. position is plotted as shown in Figure $4 \mathrm{~b}$. The minimum specific energy is obtained around $156[\mathrm{~cm}]$ position, which lies within the throat section of the Venturi constriction.

\subsection{Froude Number Study}

Froude Number is used to identify different flow conditions and the position of critical depth as shown in Figure 5. The flow is subcritical with $F r<1$, critical with $F r=1$, and supercritical with $F r>1$ as indicated in Figure 5. Tracking the corresponding position for $F r=1$, the critical depth is around $156[\mathrm{~cm}]$ position in the throat section of the Venturi constriction.

\subsection{Critical Depth Flow Model}

The volumetric fluid flow can be estimated based on the critical depth using the Equation 9. In the context of this study, the flow rate is randomly varied and the critical depth is measured at $156[\mathrm{~cm}]$ position using an ultrasonic level sensor. Figure 6 shows the comparison of estimates of critical depth flow model against the randomly varying mass flow rate setpoints. The original ultrasonic level measurements are very noisy. So, the moving average filter with last 10 samples is used to filter the noise to some extent. Both of the flow estimates with and without filtering are presented in Figure 6. The filtered estimates seem to be less noisy compared to the unfiltered estimates. However, the Mean Absolute Percentage Error (MAPE) is slightly better for unfiltered estimates.

In Figure 6, it can be seen that the estimates are comparatively much accurate for the flow rate of 350 $[\mathrm{kg} / \mathrm{min}]$. It is because the position of critical depth measurement is chosen based on the critical depth position of $350[\mathrm{~kg} / \mathrm{min}]$ flow rate. The critical depth and position of critical depth are dependent on the flow rate and rheological properties of the fluid.

Figure 7a shows the specific energy diagram of fluid flow along the Venturi constriction at different flow rates. It can be observed that with the increase in fluid flow rate, the specific energy and critical depth of the fluid increases. The primary reason for this is the increases in fluid volume. The possible secondary reason is the reduction in the viscosity of the fluid as flow rate increases for the shear thinning model-drilling fluid.

Figure $7 \mathrm{~b}$ shows the specific energy vs. position plot in the throat section of Venturi constriction. It can be observed that the minimum specific energy point is 


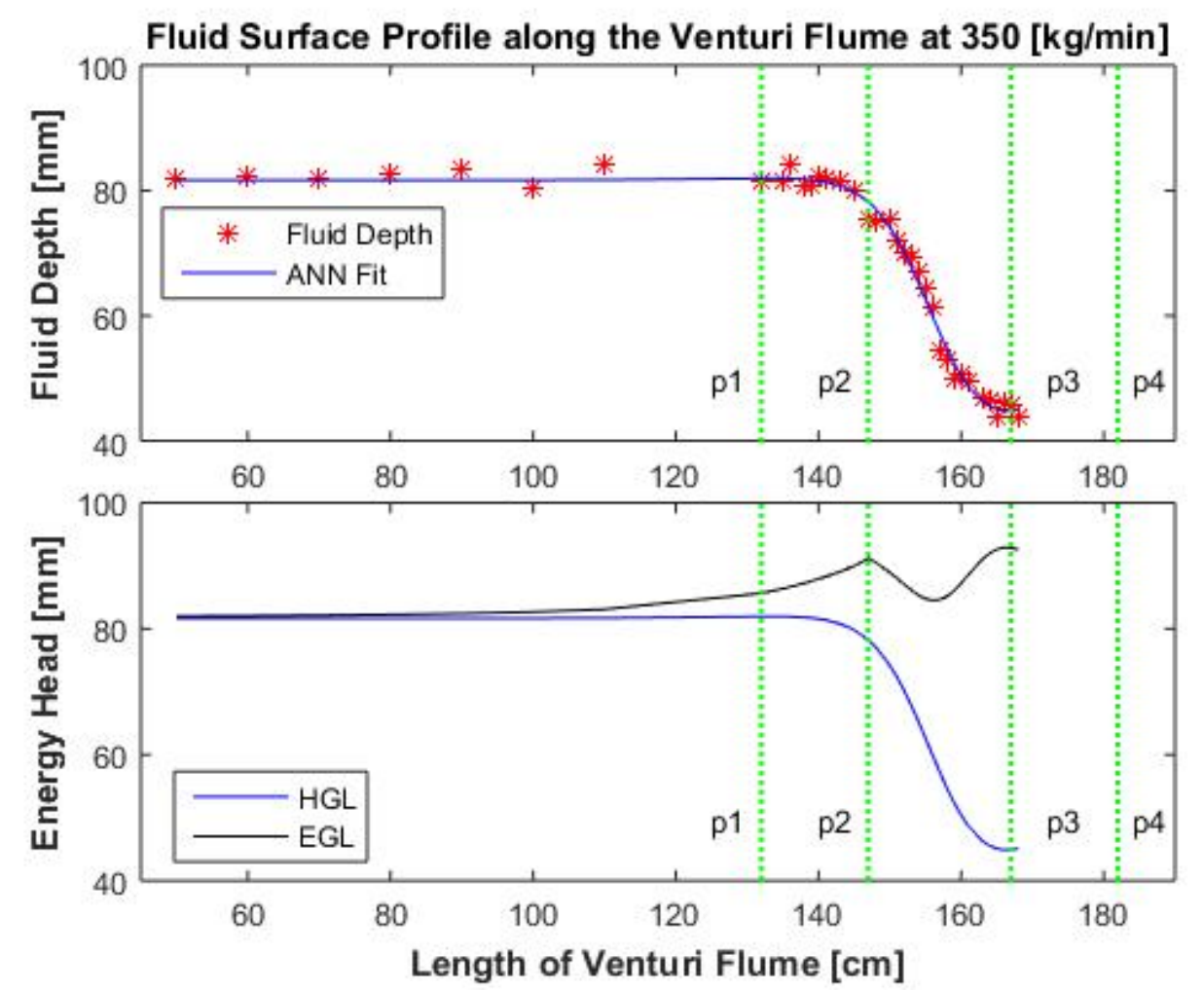

Figure 3. a) Experimental ultrasonic flow depth measurements with an Artificial Neural Network based polynomial fit. b) The Hydraulic Grade Line and Engery Grade Line along the Venturi flume at the flow rate of $350[\mathrm{~kg} / \mathrm{min}]$. The green dotted lines indicate the different sections of Venturi constriction according to Figure 2.

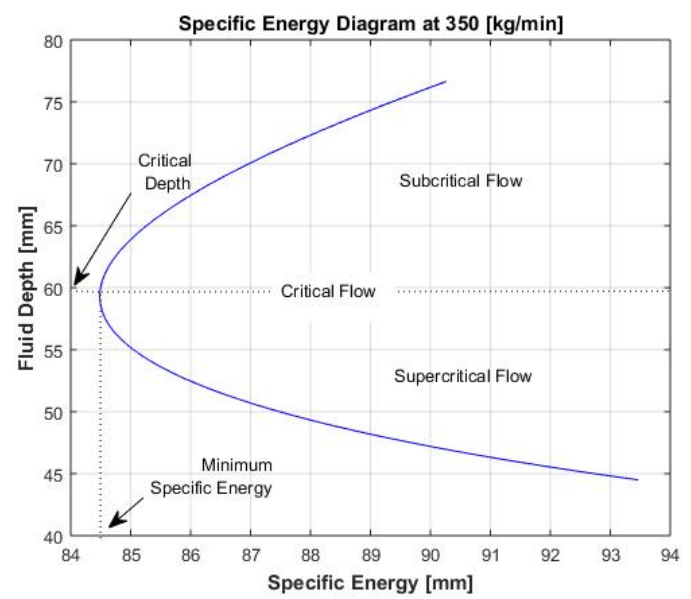

(a)

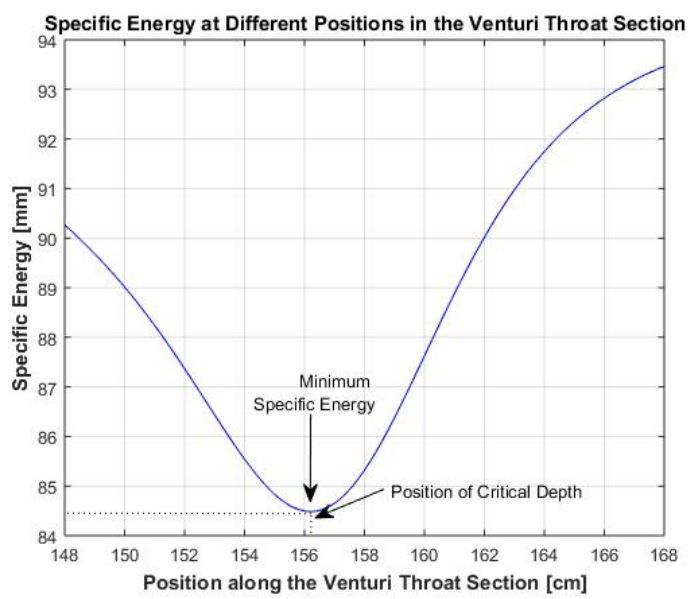

(b)

Figure 4. a) Specific energy diagram at the flow rate of $350[\mathrm{~kg} / \mathrm{min}]$ showing critical depth (at minimum specific energy point) and different flow conditions. b) Specific energy vs. position diagram showing the exact critical depth position in the Venturi constriction.

slightly shifting towards the end of the throat as the flow rate increases, giving different critical depth position for different flow rates. It is due to the momentum of the fluid flowing through the Venturi constriction. The higher flow rate fluid will flow faster within the fixed cross-section of Venturi flume, providing extra momentum as the flow rate increases.

\section{Conclusion}

In this work, one of the applications of open channel flow in the field of drilling operations is investigated. In drilling operations, non-Newtonian fluid is circulated in a closed loop from the mud tank, into the bottom-hole and back to the mud tank. The return flow is an open channel flow 

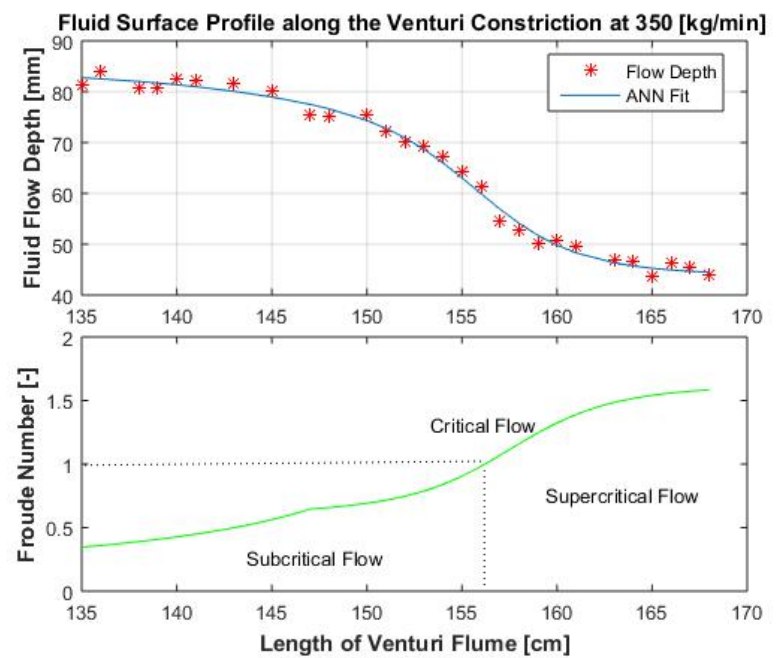

Figure 5. a) Experimental ultrasonic flow depth measurements with an Artificial Neural Network based polynomial fit. b) Froude number along the Venturi constriction showing critical depth position and different flow conditions at the flow rate of 350 [ $\mathrm{kg} / \mathrm{min}]$.

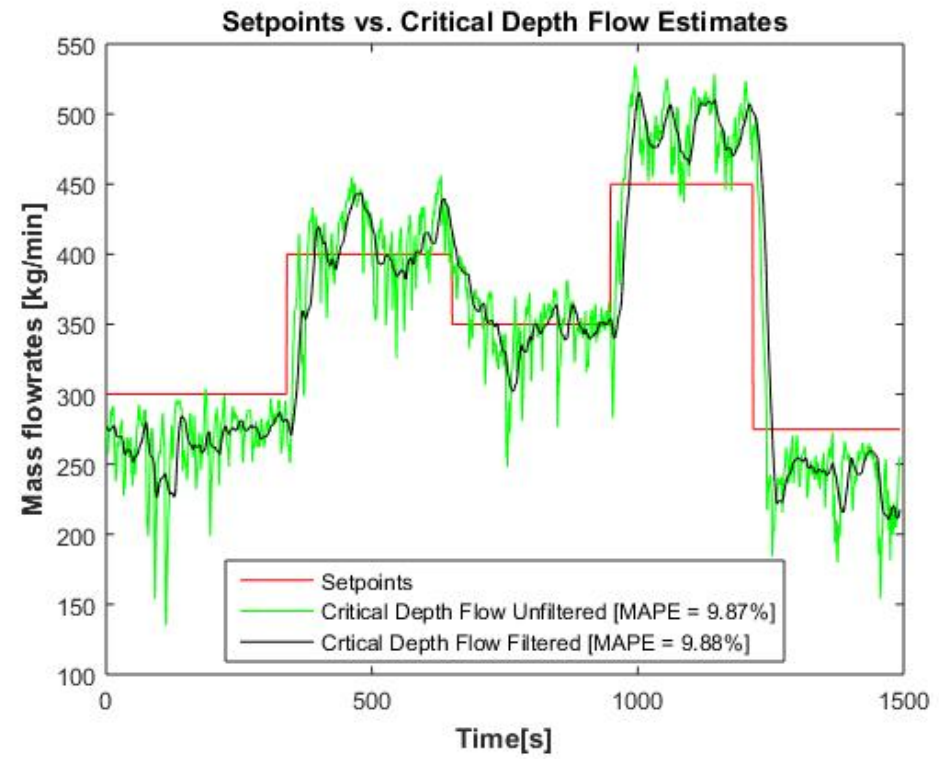

Figure 6. The comparison of estimated flow rates using critical depth (with or without filter) against the randomly varying setpoints based on Mean Absolute Percentage Error (MAPE).

and there is a need for accurate return flow for safe and efficient drilling operations. The study investigates the use of Venturi constriction in the return flow to estimate the flow rates based on the critical depth measurements using the test flow loop available at USN.

For the measurement of critical depths, specific energy diagram and Froude Number approaches are used to locate the critical depth position along the Venturi constriction. Using specific energy diagram, critical depth and critical depth position for a given flow rate are identified at the location of minimum specific energy. Using Froude Number, critical depth position is identified for the $\mathrm{Fr}$ value equal to 1 . In both approaches, different flow conditions: subcritical flow, critical flow, and supercritical flow along the Venturi flume are observed with respect to the critical depth. Further, a critical depth flow model is derived from specific energy equation, which can estimate flow rate for measured critical depth.

The detailed study is performed for $350[\mathrm{~kg} / \mathrm{min}]$ flow rate with the critical depth at $156[\mathrm{~cm}]$ position in the throat section of Venturi constriction. For randomly varying flow rates, the estimates of critical depth flow model with critical depth position at $156[\mathrm{~cm}]$ are compared with the setpoints. The comparison result shows that the estimates are within the acceptable limits. However, the estimates are more accurate for $350[\mathrm{~kg} / \mathrm{min}]$ flow as the critical depth position for $350[\mathrm{~kg} / \mathrm{min}]$ is chosen for critical depth measurement.

To investigate the effect of flow rates on critical depth, specific diagram for different flow rates are studied. 


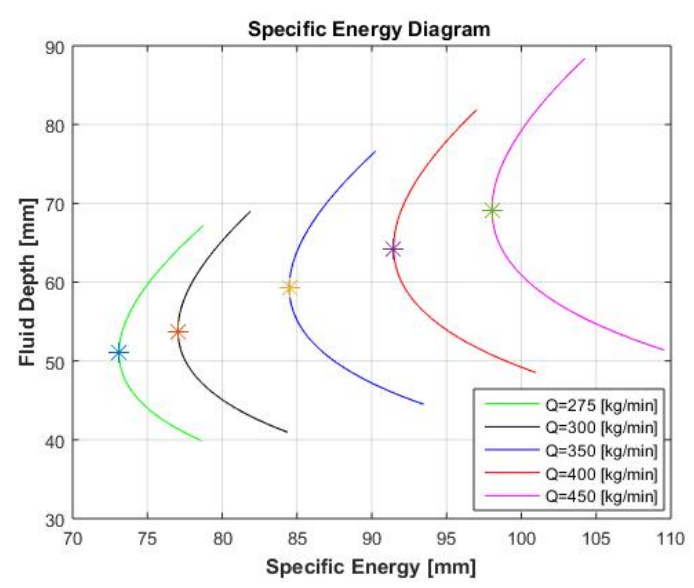

(a)

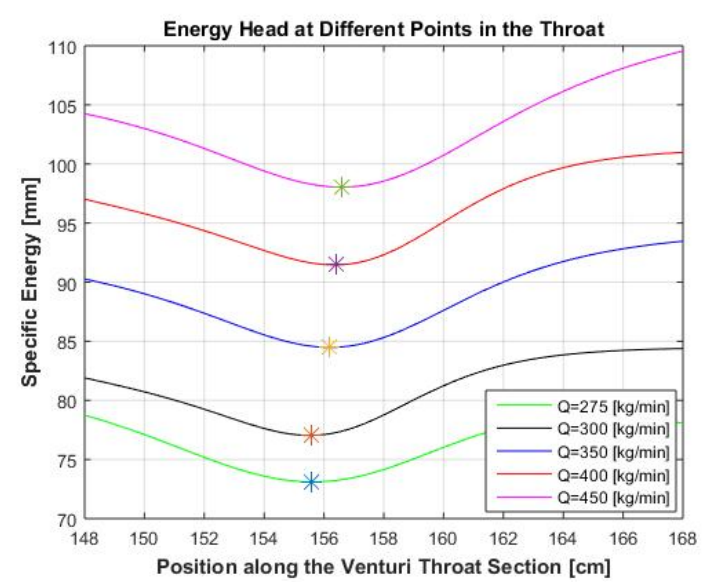

(b)

Figure 7. a) Specific energy diagram at different flow rates. b) Specific energy vs. position diagram at different flow rates. The asterisk signs with different colors indicate the point of minimum specific energy at different flow rates.

The study shows that as the flow rate increases the specific energy increases, critical depth increases, and the critical depth position shifts towards the end of the throat section. The changes are due to the increase in fluid flow momentum and change in rheological properties.

We foresee the future efforts in comparing and investigating specific energy diagrams of different model-drilling fluids at different flow rates to analyse the relation between critical depth and rheological properties.

\section{Acknowledgement}

The Ministry of Education and Research of the Norwegian Government is funding Khim Chhantyal's Ph.D. studies at USN. We acknowledge the collaboration with and support from STATOIL for providing open channel Venturi rig dedicated for flow studies of different Newtonian and non-Newtonian fluids.

\section{References}

JH Burger, R Haldenwang, and NJ Alderman. Laminar and turbulent flow of non-newtonian fluids in open channels for different cross-sectional shapes. Journal of Hydraulic Engineering, 141(4):04014084, 2014.

Johan Burger, Rainer Haldenwang, and Neil Alderman. Laminar non-newtonian open channel flow: investigating velocity, wall shear stress and fluid depth. BHR Group, 2010.

Ryen Caenn, Henry CH Darley, and George R Gray. Composition and properties of drilling and completion fluids. chapter 1, pages 7-16. Gulf professional publishing, Waltham, USA, 2011.

M Hanif Chaudhry. Open-channel flow. Springer Science \& Business Media, 2007.

Khim Chhantyal, Håkon Viumdal, Saba Mylvaganam, and Minh Hoang. Flow rate estimation using dynamic artificial neural network with ultrasonic level measurements. In The 9th Eurosim congress on modelling and simulation, Oulu, Finland. Eurosim, 2016.

RE Featherstone and Chandra Nalluri. Civil engineering hydraulics: essential theory with worked examples. chapter 8 , pages 185-248. Collins, 1982.

Christine Kabwe, Rainer Haldenwang, Veruscha Fester, and Raj Chhabra. Transitional flow of non-newtonian fluids in open channels of different cross-sectional shapes. Journal of the Brazilian Society of Mechanical Sciences and Engineering, pages 1-19, 2017.

GM Lloyd, DJ Bode, HV Nickens, SG Varnado, et al. Practical application of real-time expert system for automatic well control. In SPE/IADC Drilling Conference. Society of Petroleum Engineers, 1990.

LD Maus, JD Tannich, and WT Ilfrey. Instrumentation requirements for kick detection in deep water. Journal of Petroleum Technology, 31(08):1-029, 1979. doi:doi.org/10.2118/7238-PA.

JJ Orban and KJ Zanker. Accurate flow-out measurements for kick detection, actual response to controlled gas influxes. In SPE/IADC Drilling Conference. Society of Petroleum Engineers, 1988. doi:10.2118/17229-MS.

JJ Orban, KJ Zanner, and AE Orban. New flowmeters for kick and loss detection during drilling. In SPE Annual Technical Conference and Exhibition. Society of Petroleum Engineers, 1987. doi:10.2118/16665-MS.

DM Schafer, GE Loeppke, DA Glowka, DD Scott, and EK Wright. An evaluation of flowmeters for the detection of kicks and lost circulation during drilling. In SPE/IADC Drilling Conference. Society of Petroleum Engineers, 1992. doi:10.2118/23935-MS.

JM Speers and GF Gehrig. Delta flow: An accurate, reliable system for detecting kicks and loss of circulation during drilling. SPE Drilling Engineering, 2(04):359-363, 1987. doi:10.2118/13496-PA. 